\title{
Multivariate Analysis of Phenotypic Diversity of Landraces of Rice of West Bengal
}

\author{
Ashim Chakravorty ${ }^{1 *}$, P. D. Ghosh ${ }^{1}$ and P. K. Sahu ${ }^{2}$ \\ ${ }^{1}$ Department of Botany, Cytogenetics and Plant Breeding Section, Biotechnology Research \\ Unit, University of Kalyani, Nadia, West Bengal-741235, India. \\ ${ }^{2}$ Department of Agricultural Statistics, Bidhan Chandra Krishi Viswavidyalaya, Nadia,
}

West Bengal, India.

Authors' contributions

This work was carried out in collaboration between all authors. Author PDG designed the study, supervised the experiment and revised both the protocol and manuscript. Author AC

performed the experiment and statistical analysis, wrote the protocol and manuscript, and revised the manuscript. Author PKS helped to manage the analyses of the study. All authors read and approved the final manuscript.

Research Article

Received 11 $1^{\text {th }}$ October 2012

Accepted $7^{\text {th }}$ December 2012

Published 20 $0^{\text {th }}$ December 2012

\section{ABSTRACT}

Aims: The objectives of this study were to characterize, evaluate and work out the interrelationship among the agro-morphological traits with a view to exploiting them directly in the field (if possible) and forming a base for using these landraces in breeding program.

Study Design: A field experiment was done with fifty-one landraces of rice evaluated for 18 agro-morphological traits.

Place and Duration of Study: At the Research Farm of Zonal Adaptive Research Station Krishnagar, Nadia, West Bengal, India during the kharif season of 2008, 2009 and 2010.

Methodology: The experiment was set out in a randomized complete-block design with two replications to determine the nature and magnitude of the variability among the genetic materials, and the intensity of relationships among the traits using multivariate tools.

Results: The study analyzed the diversity of phenotypic traits of the landraces of rice. The analysis of variance found significant variability in eighteen quantitative traits used in distance analysis. All the traits except ligule length, culm length, number of grains panicle ${ }^{-1}$ and number of primary branches panicle ${ }^{-1}$ exhibited positive and significant correlation coefficients with kernel weight. Leaf length was positively and significantly correlated with 
leaf breadth $(r=0.760)$, plant height $(r=0.309)$ culm length $(r=0.352)$; plant height showed similar associationship with flag leaf angle $(r=0.337)$, culm diameter $(r=0.688)$, culm number $(r=0.706)$ and panicle length $(r=0.654)$. Principal component analysis revealed that six quantitative characters viz., leaf length, culm number, culm diameter, number of grains panicle $^{-1}$, grain length/breadth ratio and grain length significantly influenced the variation in these cultivars. Cluster analysis permitted the separation of landraces into ten major clusters from diverse geographical location, suggesting environmental adaptation of the landraces.

Conclusion: Thus, the present work identified the existence of inherent variability in the landraces of rice that could be used to exploit the variability directly or through crop improvement programs.

Keywords: Rice landraces; morphological diversity; multivariate analysis; cluster analysis ${ }^{1}$.

\section{INTRODUCTION}

Rice (Oryza sativa L.) is a major food crop, ranking second to wheat among the most cultivated cereals in the world [1]. In India, it is a dominating staple food crop of fertile and alluvial soils of North East India, particularly the Indo Gangetic plains [2]. It occupies 43.8 million hectares of land with a total production of 96.4 million tons of rice [3].

The rice growing regions of alluvial zone of West Bengal include a range of diverse agroecological niches with a number of diverse lines. Though once (before 1970's) all the rice fields of Bengal were occupied by a number of traditional lines, in the post-green revolution period i.e. starting from early seventies to till date, a good number of such lines were replaced by high yielding rice lines. It is increasingly felt that the effect of green revolution is not going to sustain the production requirement of the country along with some adverse effects like heavy utilization of ground water and residual effects of chemicals on environment. As such, the exploitation of a vast indigenous gene pool is being talked $[4,5]$ particularly under a diminishing resource and environmental degradation scenario. Fortunately, some workers in some restricted pockets used to maintain some traditional rice lines of Bengal that were reportedly tolerant to a number of biotic stresses. Assessment of genetic diversity is very important in rice breeding from the standpoint of selection, conservation and proper utilization [6]. The role of a broad genetic base and systematically characterized germplasms in the crop improvement of cultivated plants has been well recognized. To meet the continuously expanding needs of varietal improvements, the evaluation and characterization of all of existing germplasms are needed.

Genetic variability studies are important in selection of parents for hybridization [7] as sound crop improvement depends upon the magnitude of variability in the base population [8]. Genetic variability ensures crop improvement through the use of appropriate selection methods. Measures to broaden the genetic base, such as, new introductions are needed in crops whose genetic base has become narrow for important desirable traits. Evaluation and characterization of innumerable native genotypes, which are suitable in one or more aspects, are a pre-requisite for any crop improvement program. Thus, for the effective utilization of the introductions, germplasm evaluation is a most essential step.

Landraces offer a valuable gene pool for future breeding $[9,10]$. Accurate assessment of the levels and patterns of genetic diversity can be invaluable in crop breeding for diverse 
applications, including (i) analysis of genetic variability in landraces of traditional rice cultivars [11] (ii) identifying diverse parental combinations to create segregating progenies with maximum genetic variability for further selection [12] and (iii) introgressing desirable genes from diverse germplasm into the available genetic base [13].

Multivariate statistical tools have found extensive use in summarizing and describing the inherent variation among crop genotypes. One of the tools includes principal component analysis (PCA). This technique identifies plant traits that characterize the distinctness among selected genotypes. These are often extended to the classification of a population into groups of distinct orders based on similarities in one or more characters, and thus guide in the choice of parents for hybridization [14,15]. The PCA has been used to partition observed agronomic variations into genotypes of many crops, such as rubber [16], rice [17] and sesame [18]. Various workers studied the relationships between different traits in different crops, such as, soybean [8], cassava [19]. While PCA helps to identify the traits with the highest variability, correlations reveal the strength of relationships of the identified traits with yield and other traits, which makes the development of new varieties efficient and effective. Correlation studies enable the breeder to understand the mutual component characters on which selection can be based for genetic improvement. Many economically important traits of plants are usually related to one another in one or several ways. This apart, the knowledge on the nature and magnitude of genetic variation governing the inheritance of quantitative characters, such as, yield and its components, is essential for effecting genetic improvement and for adopting appropriate selection techniques.

The genetic improvement of any crop is highly dependent on the magnitude of several genetic parameters, such as, analysis of variance of each mean value, phenotypic and genotypic variances, phenotypic and genotypic coefficient of variation (PCV and GCV), broad sense heritability and genetic gain on which the breeding methods are formulated for its further improvement. The extent of variability is measured by genotypic coefficient of variance and phenotypic coefficient of variance which provide information about relative amount of variation in different characters.

To have proper characterization and evaluation of landraces, the above tools are found to be useful for exploitation of the characters and the landraces in further breeding program. As such, this study has used these tools to make the study an exhaustive one.

Keeping in view these facts, the present investigation aims to characterize a set of landraces of rice of Gangetic alluvium zone of West Bengal to ascertain their variability and diversity in situ for different morphological and agronomical traits. Characterization of landraces could help breeders to utilize appropriate characters in rice improvement programs. The study aims at providing the base material for the rice breeders for exploitation of landraces possessing one or more desirable characters.

\section{MATERIALS AND METHODS}

\subsection{Experimental Site}

The study was carried out at a research farm of Zonal Adaptive Research Station, Krishnagar, Nadia, West Bengal, during the autumn (June-December) seasons for three consecutive years of 2008, 2009 and 2010 . The experimental site $\left(23^{\circ} 24^{\prime} \mathrm{N}\right.$ latitude and $88^{\circ} 31^{\prime} \mathrm{E}$ longitude with an altitude of 9.75 meters above sea level) has humid climate (mean 
rainfall $=1496 \mathrm{~mm}$; most of the rainfall occurring between June and September). Threefourths of the annual rainfall is obtained during June to September and about $84 \%$ during June to October. Temperature ranges from $7.6^{\circ} \mathrm{C}$ to $41^{\circ} \mathrm{C}$. The soil at the research farm is alluvium, slightly acidic $(\mathrm{pH}=6.0)$, and suitable for rice cultivation.

\subsection{Experimental Material, Design and Field Management}

Fifty-one rice landraces (Table 1), collected from different locations across the alluvium zone of West Bengal, India, were evaluated in a randomized complete-block design.

Table 1. List of various cultivars with their respective codes and their source of collection

\begin{tabular}{|c|c|c|c|c|c|}
\hline Code & $\begin{array}{l}\text { Name of the } \\
\text { cultivars }\end{array}$ & $\begin{array}{l}\text { Place of } \\
\text { collection }\end{array}$ & Code & $\begin{array}{l}\text { Name of the } \\
\text { cultivars }\end{array}$ & $\begin{array}{l}\text { Place of } \\
\text { collection }\end{array}$ \\
\hline G1 & Ranisal & Z.A.R.S, & G27 & Laldhusri & Z.A.R.S. \\
\hline $\mathrm{G} 2$ & Badhabna & , & G28 & Malliksal & ," \\
\hline G3 & Machkata & , & G29 & Baidjhulur & , \\
\hline G4 & Laldhula & , & G30 & Jhulur & ", \\
\hline G5 & Dhuladhan &, & G31 & Manikanchan &, \\
\hline G6 & Dhuri &, & G32 & Nagra & ," \\
\hline G7 & Kalamkathi(W) &, & G33 & Danaguri & , \\
\hline G8 & Suakalama & , & G34 & Majhisal & ," \\
\hline G9 & Nakrasal &, & G35 & Basmoti Local & ," \\
\hline G10 & Asanlaya(white) &, & G36 & Netaisal &, \\
\hline G11 & Asanlaya(red) & , & G37 & Sankar kalma & , \\
\hline G12 & Pubalgara & , & G38 & Rupsal & , \\
\hline G13 & Daharnagra & , & G39 & Jhingasal & ," \\
\hline G14 & Kalonunia &, & G40 & Sungakalma & ," \\
\hline G15 & Tulsibhog &, & G41 & Jhuli &, \\
\hline G16 & Mashisladan & , & G42 & Raja Badsa & ," \\
\hline G17 & Dudhkalama & ," & G43 & kalma & ," \\
\hline G18 & Sankarsal &, & G44 & Sunga Nagra & ," \\
\hline G19 & Badsabhog & , & G45 & Kerala Sundari & , \\
\hline G20 & Agnisal &, & G46 & Balaram sal & , \\
\hline G21 & Chadrakanta & , & G47 & Danga & ," \\
\hline G22 & Muktasal & , & G48 & Asanlaya &, \\
\hline G23 & Punjabsal &, & G49 & Lalhusri & ," \\
\hline G24 & Sitasal &, & G50 & Annanda &, \\
\hline G25 & Behalsal & ," & G51 & Sarkele(aman) & ," \\
\hline G26 & Kabirajsal &, & \multicolumn{3}{|c|}{$\begin{array}{l}\text { *Z.A.R.S : Zonal Adaptive Research Station, } \\
\text { Nadia, West Bengal }\end{array}$} \\
\hline
\end{tabular}


Seedlings of each entry were transplanted in a $3 \times 2.85 \mathrm{~m}^{2}$ plot with plant to plant spacing of $15 \mathrm{~cm}$ within a row and row to row spacing of $20 \mathrm{~cm}$. Plot to plot distance was $60 \mathrm{~cm}$. Crop was raised following the recommended package of practices. Data were collected on 18 agro-morphological traits. The individual genotypic means were subjected to an analysis of variance followed by an Least Significant Difference (LSD) test. The landraces $x$ years interaction effects were not significant and hence the pooled data were used for calculation using SPAR1 (Statistical Package for Agricultural Research, developed by IASRI, 1991). The total variance was partitioned into genotypic and phenotypic components. The genotypic and phenotypic correlation coefficient values were calculated as per Steel and Torrie (1997) [20]. Cluster analysis based on Euclidean distances between the fifty one landraces was carried out. Multivariate tool used for analyzing data was principal component analysis (PCA). The PCA was calculated by SPAR1 (Statistical Package for Agricultural Research, developed by IASRI, 1991).

\section{RESULTS AND DISCUSSION}

Analysis of variance indicated that the difference among landraces for all the characters under study was highly significant $(\alpha=0.01)$ except culm diameter. Univariate statistical analysis gave an excellent opportunity to identify and group the genotypes into different categories with respect to various characters individually. Studies on quantitative characters have earlier been made [21]. Leaf length had mean value of $47.47 \mathrm{~cm}$ with a wide variation from $34.0 \mathrm{~cm}$ (Ranisal) to $61.0 \mathrm{~cm}$ (Jhingasal). Most of the lines $(58.8 \%)$ were in the range of $44.0-53.0 \mathrm{~cm}$. Highest leaf breadth value $(2.20 \mathrm{~cm})$ was obtained in Rupsal (G38) and Sitasal (G24). Maximum plant height $(43.0 \mathrm{~cm})$ was observed in variety Sarkele aman (G51), while minimum $(24.0 \mathrm{~cm})$ in Tolsibhog (G15). Plant height in rice is a complex character and is the end product of several genetically controlled factors [22]. Reduction in plant height may improve their resistance to lodging and reduce substantial yield losses associated with this trait [23]. The success of the "green revolution" is directly related to the intensive use of the semi-dwarf varieties [24]. The semi dwarf plant type has been extensively utilized in the improvement of rice (O. sativa L.) cultivars throughout the world. In Kerala, farmers want tall rice so that they can feed its straw to cattle. However, tall varieties lodge when heavily fertilized, significantly reducing yields. Thus, there has been a desire to combine desirable characteristics of tall varieties with yielding ability and a new type of architecture is intermediate plant height. These varieties could be used in breeding program to combine with other favorable characters.

In this collection of landraces, one can find wide range of variation in flag leaf angle which could be utilized in crop improvement program. The highest flag leaf angle has been found in varieties, like, Sarkele aman (G51), Asanlaya (G48), Baloramsal (G46), Jhingasal (G39), Sankarkalma (G37), Behalsal (G25), Punjubsal (G23) and Agnisal (G20) which are significantly different from the rests. The lowest value has been found among the varieties like Laldhula (G4), Dhuri (G6), Kalamkathi (G7), Asanlaya(red) (G11), Dudhkalma (G17), Sankarsal (G18), Muktasal (G22), Nagra (G32) and Danaguri (G33). Breeding for erect leaf has been suggested as a method of increasing grain yield in cereal crops. Increasing light penetration into crop canopy has been suggested as one of the way of obtaining higher grain yield. Increased penetration of light into canopy would increase photosynthetic rate and perhaps enhance grain yield [25]. It has been found that erect leaf angle was associated with high yield in rice (O. sativa L.) [26]. In case of ligule length, variety Sarkele aman (G51) had the maximum value followed by Manikanchan (G31), Laldhusri (G27) and Kabirajsal (G26). Regarding culm length, it had mean value of $133.99 \mathrm{~cm}$ and a wider range of variation from $94-151 \mathrm{~cm}$ was recorded. Most of the lines were in the range of $130-151 \mathrm{~cm}$. 
Regarding the panicle length, maximum value $(30.5 \mathrm{~cm})$ was obtained in Sarkele aman (G51). It exhibited reasonable amount of variation $21.0-30.50 \mathrm{~cm}$ with average being 20.1$25.0 \mathrm{~cm}$. Variety Malliksal (G28) had the maximum value $(11.2 \mathrm{~mm})$ for grain length. Regarding the grain length, this also exhibited reasonable amount of variation with range value of $3.90-11.2 \mathrm{~mm}$. Cultivar with minimum grain length $3.90 \mathrm{~mm}$ was Tulsibhog. In case of grain breadth, the highest value $(4.2 \mathrm{~mm})$ was obtained in Sarkele aman (G51) and the minimum value recorded for grain breadth was $2.05 \mathrm{~mm}$ for Kalma. Grain size and shape are among the first criteria of rice quality that breeders consider in developing new varieties for releasing for commercial production [27]. In respect to grain weight, the maximum value (29.91g) was found in Sarkele aman (G51) followed by Jhingasal (G39), Suakalma (G8) and Sitasal (G24). In case of 1000 grain weight, most of the lines were in the range of 10.34$29.91 \mathrm{~g}$. Lines with high grain weight were also observed in this set of germplasm. Variety Jhingasal (G39) had maximum value in case of kernel weight.

In case of days to maturity, they exhibited high range (116-172days) along with grand mean of 139.94 days. Netaisal had shorter maturity period, i.e. 116 days, representing earliness. Variations in duration of crop could be utilized directly under varied agro-ecological situation as well as in breeding program. In case of primary branches panicle ${ }^{-1}$, Majhisal (G34) and Danaguri (G33) had maximum value (17). Regarding number of grains panicle ${ }^{-1}$, the highest value was obtained in Machkata (G3) and Basmoti local (G35).

In case of number of grains panicle ${ }^{-1}$, they exhibited high range of variation with the range from 30.0 (Sankarsal) to 334.0 (Basmoti local). It has been found to have maximum accessions within the range of $112-194$ grains panicle ${ }^{-1}$. Since, greater number of grains panicle ${ }^{-1}$ is one of the major criteria which contribute to higher grain yield [28], this could be utilized in further program.

Genetic variability studies showed that GCV ranged from 8.66 to 35.28. Number of grains panicle $^{-1}(40.86)$ had the highest GCV followed by flag leaf angle (40.39). High heritability estimates were observed for all the traits. Heritability was over $50 \%$ in the characters, such as, grain weight, kernel weigh and days to maturity. So, these estimates are helpful in making selection on the basis of phenotypic performance. Some additive portion of genetic variance is fixable in nature; so the selection of these traits is expected to be effective. For effective selection, genetic advance was computed because high heritability does not necessarily mean an increased genetic response to signify the selective advantage accruing in an additive character [29]. Hence, one has to consider high heritability estimates and high genetic advance together to select better potent with desirable additive effect [30]. Also, it is suggested that the genotypic coefficient of variation together with heritability estimates gave the better picture of the extent of heritable variation [31]. So, the present study showed the positive juxtaposition of the three factors, viz., genotypic coefficient of variation (GCV), heritability and genetic advance, for the effective crop improvement program. Characters like flag leaf angle, ligule length, culm diameter, culm number number of primary branches panicle $^{-1}$, number of grains panicle ${ }^{-1}$ and 100 kernel weight showed high amount of GCV along with high heritability and high genetic advance. These characters could be improved directly through selection. This indicated the predominance of additive gene action in expression of these traits [30,32].

Thus, from the study of individual characters, it is clear that there exist huge variations in all the characters among the germplasms which could be directly used in the field and or may be used for crop improvement program. 


\subsection{Correlation Studies}

Correlation results of 18 traits are presented in Table 2. Generally, all the traits except ligule length, culm length and culm diameter exhibited positive and significant $(P<0.01$ and $\mathrm{P}<0.05)$ correlations with kernel weight, which appeared to be amenable for simple selection for future breeding program. Characters such as grain weight (0.988), grain length $(0.508)$, grain breadth (0.196), flag leaf angle (0.137), showed significant positive associations with the kernel weight whereas ligule length, culm length, culm diameter showed negative correlation with the kernel weight. Grain weight showed highest correlation $(r=0.988)$ with kernel weight followed by grain length $(r=0.508)$. Maturity was poorly correlated with other morphological agronomic traits. It exhibited negative correlation with nine traits and found significantly correlated with flag leaf angle $(r=0.32)$ and plant height $(r=0.058)$. This indicates that some cultivars had erect flag leaf angle and taller plant height. The participation of non laminar photosynthesis in grain filling is quite evident in the correlation between grain weight and sterile lemma length. Sterile lemmas contribute to the total photosynthates stored in the grains. Plant height was significantly correlated $(r=0.306)$ with leaf length showing the principle of morphogenic compatibility in the architectural plant type in rice. Based on correlation analysis, a number of traits were directly associated with other traits regardless of plant type or architectural configuration of the whole plant.

\subsection{Principal Component Analysis}

As it has been found that the characters are interrelated, so to have an idea about their independent impact, principal component analysis was undertaken. The first six components in the PCA analysis with eigenvalues $>1$ contributed $75.9 \%$ of the variability among genotypes evaluated for different agro-morphological traits (Table 3). Other PCs (7-16) had eigenvalues less than 1. Principal component one (PC1), with eigenvalue of 3.755 , contributed $23.47 \%$ of the total variability, while PC2 with eigenvalue of 2.246 accounted for $14.039 \%$ of total variability observed among 51 landraces of rice genotypes. PC3 had eigenvalue of 2.047 and contributed $12.79 \%$ to the observed variability. PC4, PC5 and PC6 had eigenvalues of $1.632,1.293$ and 1.159 respectively and contributed $10.19 \%, 8.07 \%$ and $7.24 \%$ of the total variability.

For each principal axis, there are a number of characters contributing to the total variation (Table 3). In PC1, the traits that accounted for most of the $23.47 \%$ observed variability among 51 genotypes included leaf length, with loading of 0.625 , plant height $(0.751)$, culm diameter (0.780), culm number (0.802) and panicle length (0.697). PC2 is related to leaf width $(-0.521)$, ligule length $(0.412)$, number of primary branches panicle ${ }^{-1}(0.804)$ and number of grains panicle ${ }^{-1}(0.709)$. PC3 was more related to grain breadth $(-0.660)$ and grain length/breadth ratio (0.707). PC4 was related to flag leaf angle $(0.574)$, maturity $(0.511)$ and sterile lemma length (0.574). PC5 included grain length (0.630) while PC6 was related to culm length (0.552). 
Table 2. Genotypic and Phenotypic correlation coefficients among eighteen quantitative traits of 51 traditional rice cultivars

\begin{tabular}{|c|c|c|c|c|c|c|c|c|c|c|c|c|c|c|c|c|c|c|}
\hline & h1 & h2 & 3 & 4 & 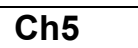 & 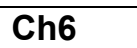 & 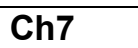 & 8 & 19 & & & & & h14 & & & Ch17 & \\
\hline$\cdots$ & & 700 & & & & - & & & & & & & & & & & & 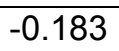 \\
\hline & & & 089 & & & & & & & & & & & & & & & \\
\hline & & 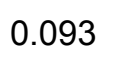 & & & 72 & $r$ & & & & & 4 & & & & & & & \\
\hline & & 243 & 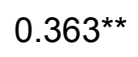 & & & 2 & & & 1 & 58 & & & 49 & & $8^{x}$ & 23 & & 24 \\
\hline & & 000 & 0.084 & 7 & & & $337^{*}$ & 39 & 081 & .210 & $39^{\pi x}$ & 6 & .115 & 60 & 0.249 & 32 & 3 & 050 \\
\hline & & $0.460^{* *}$ & 0.168 & .040 & 0.190 & & & 136 & 160 & .231 & 001 & 0.198 & .074 & 00 & 0.003 & 94 & 0.020 & 118 \\
\hline & 3 & 099 & 0740 & 211 & $0.353^{* *}$ & $0.362^{* *}$ & & 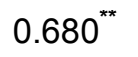 & $532^{\pi \pi}$ & -0.106 & .009 & 0.089 & 0.028 & 17 & 0.161 & -0.136 & $.325^{x}$ & 48 \\
\hline & & 0 & $x^{2}>$ & 1 & 8 & * & & & 611 & 1 & 5 & 9 & 6 & & & 3 & & 33 \\
\hline & & 7 & * & 2 & 3 & ** & 0.6 & & & -0 & 5 & 4 & 9 & & & & & 65 \\
\hline & & 2 & -( & 65 & & 32 & +3 & 2 & -0.180 & & & $7^{\pi \pi}$ & $0.437^{\pi \pi}$ & & 0.029 & $0.424^{\star \pi}$ & & 32 \\
\hline & & T & & 2 & . & c & & מרח ח & 1 & 0 & & 621 & $0.327^{\pi}$ & & & & & \\
\hline & & -0.247 & 34 & 34 & -0.513 & 8 & 17 & -0.123 & 03 & $0.531^{* *}$ & 0 & & 3 & & 16 & & & -0.056 \\
\hline & & & & & -0.120 & -0.092 & 0.028 & 0.1 & 0.122 & $0.490^{* *}$ & $28^{*}$ & 0. & & $0.982^{\star \pi}$ & & & & -0.167 \\
\hline & & & & & & & & & 78 & $508^{* *}$ & & & 0.900 & & & & & -0.164 \\
\hline & & 6 & & 51 & -0. & 8 & & . & 93 & 24 & & & 45 & & & 0.218 & & 49 \\
\hline & & -0 . & -0.258 & דים & -0 & -0 & -0 & 45 & -0.425 & $0.694^{*}$ & 27 & & 30 & & $0.286^{*}$ & & 82 & 0.214 \\
\hline & & 0.152 & .079 & -0.017 & 0.273 & 0.025 & $0.330^{*}$ & 0.229 & -0.032 & -0.118 & & & 0.010 & & -0.194 & 0.148 & & $0.761^{\pi \pi}$ \\
\hline Ch18 & .213 & 0.213 & -0.027 & 0.027 & -0.060 & -0.096 & 0.055 & & -0.262 & & & & -0.197 & 0.190 & 0.052 & $0.372^{* *}$ & $846^{*}$ & \\
\hline
\end{tabular}

Ch1: leaf length Ch2: leaf breadth Ch3: plant height Ch4: flag leaf angle Ch5: ligule lengthCh6: culm length Ch7: culm diameter Ch8: culm no. Ch9: panicle length Ch10: grain length Ch11: grain breadth Ch12: grain L/B ratio Ch13: grain weight Ch14: kernel weight Ch15: maturity Ch16: sterile lemma length Ch17: primary branches panicle ${ }^{-1}$ Ch18: number of grains panicle

*and**indicate significance at 5\% and 1\% levels, respectively. Upper diagonal correlations are genotypic correlations and lower diagonal correlations are phenotypic correlation. Correlation coefficient $r>0.276$ and $r>0.351$ are significant at $5 \%$ and $1 \%$ level. 
Thus, the prominent characters coming together in different principal components and contributing towards explaining the variability have the tendency to remain together which may be kept into consideration during utilisation of these characters in breeding program. Five characters, viz., leaf length, plant height, culm diameter, culm number and panicle length, contributed positively to PC1; thus, this component is the weighted average of the characters which are both vegetative and reproductive in nature. In PC1, culm number exhibited the greatest positive weight. The characters with positive weight in PC2 were number of primary branches per panicle followed by number of grains per panicle and ligule length; thus, this component is weighted by both vegetative and reproductive characters. The character with positive weight in PC3 was grain length/breadth ratio $(0.707)$ which is reproductive in nature. The above findings suggest that somewhere, as in PC1 and PC2, each of the accessions contributes both vegetatively and reproductively and, in some cases, each accession contributes only one-sidedly, either reproductively or vegetatively, as reproductively in PC3. PCA is a technique which identifies plant traits that contribute most of the observed variation within a group of genotypes. The tool has a practical application in the selection of parent lines for breeding purposes. The cumulative variance of $75.9 \%$ by the first six axes with eigen value of $>1.0$ indicates that the identified traits within the axes exhibited great influence on the phenotype of the landraces, and could effectively be used for selection among them.

Table 3. Principal component analysis of 18 agro-morphological traits for 51 landraces of rice

\begin{tabular}{lllllll}
\hline Variables & \multicolumn{7}{l}{ Component } & & & & \\
\cline { 2 - 7 } & PC1 & PC2 & PC3 & PC4 & PC5 & PC6 \\
\hline Leaf length & .625 & -.393 & -.316 & .206 & .285 & .200 \\
Leaf breadth & .406 & -.521 & -.369 & .280 & .196 & .373 \\
Plant height & .751 & -.030 & .448 & .074 & -.022 & -.237 \\
Flag leaf angle & .329 & -.247 & .038 &. $\mathbf{5 2 4}$ & -.435 & -.252 \\
Ligule length & .368 & .412 & -.404 & -.292 & .241 & -.134 \\
Culm length & .451 & -.156 & -.233 & -.024 & .015 & .552 \\
Culm diameter & .780 & .194 & .319 & .016 & .122 & -.036 \\
Culm number & .802 & .071 & .324 & -.010 & .038 & -.033 \\
Panicle length & .697 & -.146 & .355 & -.158 & -.022 & -.178 \\
Grain length & -.301 & -.266 & .217 & .290 & .693 & -.289 \\
Grain breadth & .188 & .281 & -.660 & .223 & .221 & -.469 \\
Grain L/B ratio & -.351 & -.212 & .707 & -.115 & .239 & .230 \\
Maturity & -.127 & -.396 & -.033 &. $\mathbf{5 1 1}$ & -.420 & -.109 \\
Sterile lemma length & -.378 & -.008 & .203 &. $\mathbf{5 7 4}$ & .349 & -.010 \\
No. of pri.br./panicle ${ }^{-1}$ & .196 & .804 & .088 & .364 & .092 & .233 \\
No. of grains panicle ${ }^{-1}$ & -.064 & .709 & .160 & .499 & -.121 & .284 \\
Eigen value & 3.755 & 2.246 & 2.047 & 1.632 & 1.293 & 1.159 \\
\%vvariance contribution & 23.468 & 14.039 & 12.796 & 10.198 & 8.078 & 7.245 \\
Cumulative variance contribution & 23.468 & 37.507 & 50.303 & 60.502 & 68.580 & 75.825 \\
\hline
\end{tabular}

Extraction Method: Principal component analysis (PCA) for kernel weight. 


\subsection{Cluster Analysis}

An attempt was made to visualize the clustering pattern using the first two principal components of the principal component analysis. 10 clusters could be framed (Fig. 1). The mean performance of the clusters is presented in Table 4. Genotype G3 (Ranisal) alone formed cluster 1 , mainly attributing to minimum leaf length, panicle length and at the same time showing maximum number of grains panicle ${ }^{-1}$ and number of primary branches panicle ${ }^{-1}$ and second lowest time to maturity in days. G34 and G35 form cluster 2 as they show maximum leaf length, culm length, number of primary branches per panicle and second highest value of leaf length and number of grains per panicle. This cluster is also attributed by minimum grain length/breadth ratio and the lowest time to maturity in days. The specialty of cluster 3 lies in its minimum leaf breadth and culm number, maximum flag leaf angle and grain length, second maximum grain length/breadth ratio, kernel weight, and sterile lemma length and third maximum days to maturity. Cluster 4 shows the average mean value of all the characters. Cluster 5 shows the highest value in case of plant height and culm number. G2 alone forms cluster 6 which shows minimum leaf breadth and sterile lemma length, second minimum value of flag leaf angle and second maximum days to maturity. The specialty in cluster 7 lies in its minimum flag leaf angle and ligule length, maximum grain length/breadth ratio and third lowest time to maturity. Cluster 8 is noticeable as it shows almost average value of eighteen characters.

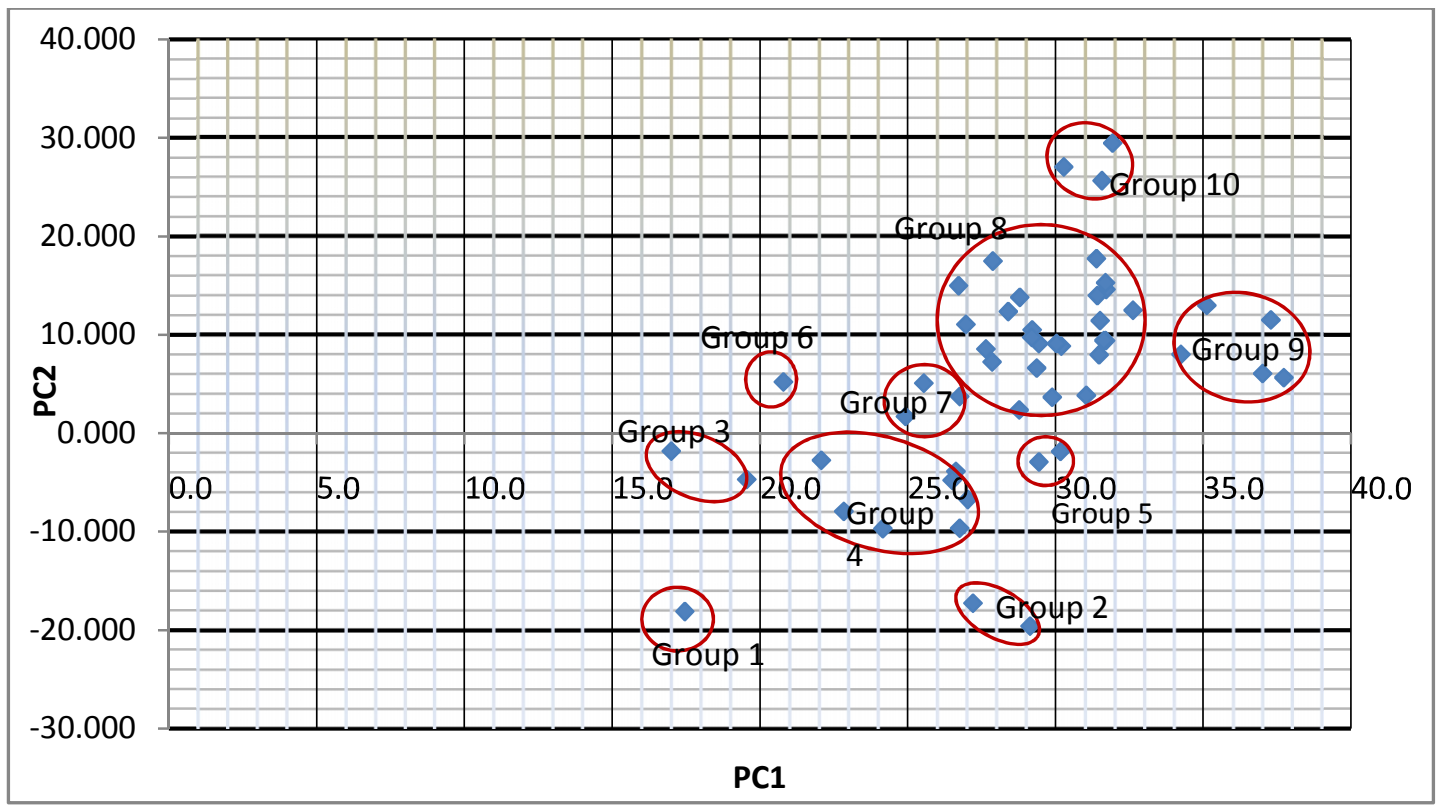

Fig. 1. Clustering of 51 landraces of rice based on 18 agromorphological characters from principal component analysis. All groups have been allocated and presented in table 4 
Table 4. Per Se performance of agro-morphological characters of landraces of rice under different clusters

\begin{tabular}{|c|c|c|c|c|c|c|c|c|c|c|c|}
\hline Grou & $\begin{array}{l}\text { No of } \\
\text { genotypes }\end{array}$ & Genotypes & Ch1 & Ch2 Ch3 Ch4 Ch5 Ch6 & Ch7 Ch8 & Ch9 Ch10 & Ch11 & $1 \mathrm{Ch} 12$ & 2 Ch13 Ch14 Ch15 & Ch16 & Ch17 Ch18 \\
\hline 1 & 1 & G3 & 35.50 & 1.2025 .002 .002 .00107 .00 & 0.508 .50 & 21.009 .34 & 3.10 & 3.01 & 20.7216 .75124 .00 & 2.00 & 16.00318 .50 \\
\hline 2 & 2 & G34,G35 & 51.50 & 1.7032 .252 .502 .08150 .50 & 0.509 .50 & 25.007 .32 & 3.20 & 2.31 & 18.6216 .00123 .75 & 51.00 & 16.00311 .00 \\
\hline 3 & 2 & G1, G20 & 39.25 & 1.2026 .503 .002 .0395 .75 & 0.406 .25 & 22.259 .40 & 3.03 & 3.11 & 22.2119 .55152 .50 & 1.50 & 14.75254 .50 \\
\hline 4 & 6 & G4,G22,G14,G29,G21,G15 & 44.00 & 1.4226 .002 .001 .59138 .17 & 0.478 .08 & 23.257 .22 & 3.04 & 2.97 & 17.1614 .21145 .25 & 51.42 & 14.17239 .00 \\
\hline 5 & 2 & G45,G47 & 47.00 & 1.3538 .752 .001 .85132 .00 & 0.6011 .75 & 28.508 .20 & 3.20 & 2.75 & 21.4918 .25138 .00 & 1.25 & 13.25224 .00 \\
\hline 6 & 1 & $\mathrm{G} 2$ & 36.00 & 1.2025 .002 .002 .10105 .00 & 0.408 .50 & 21.508 .60 & 3.70 & 2.32 & 21.3318 .25159 .00 & 1.00 & 13.00188 .00 \\
\hline 7 & 3 & G7,G6,G9 & 39.67 & 1.2727 .331 .671 .23128 .33 & 30.437 .83 & 23.838 .93 & 2.58 & 3.51 & 22.3819 .00129 .67 & 71.33 & 10.83177 .50 \\
\hline 8 & 26 & $\begin{array}{l}\text { G5,G8,G10,G12,G13,G16, } \\
\text { G17,G19,G23,G25,G26, } \\
\text { G27,G28,G30,G31,G32, } \\
\text { G33, G36, G37, G38, G39, } \\
\text { G41, G42, G43, G44, G46 }\end{array}$ & 49.04 & 1.5628 .522 .541 .83134 .71 & 0.468 .58 & 24.878 .40 & 3.06 & 2.84 & 21.7118 .51138 .92 & 21.21 & 10.96142 .33 \\
\hline 9 & 5 & G40,G48,G49,G50,G51 & 53.00 & 1.5940 .602 .802 .37148 .80 & 0.8013 .10 & 28.007 .96 & 3.20 & 2.57 & 23.2219 .30134 .50 & 1.00 & 12.90145 .30 \\
\hline 10 & 3 & G11,G18,G24 & 50.33 & 31.8325 .001 .671 .43134 .67 & 0.338 .17 & 24.509 .21 & 3.08 & 2.98 & 24.9421 .66160 .17 & 71.17 & $6.83 \quad 55.17$ \\
\hline
\end{tabular}


The distinctiveness of cluster 9 is in its maximum leaf length, plant height, culm diameter, culm number and second highest value for culm length, panicle length, grain length, grain breadth, grain weight, and minimum sterile length. Cluster 10 is made distinct for its minimum flag leaf angle and maximum leaf breadth, grain weight and kernel weight. It is also noted for maximum days to maturity and minimum number of grains panicle ${ }^{-1}$, number of primary branches panicle ${ }^{-1}$. This leads to the suggestion that varieties and the process associated with the varietal development (varietal selection) are essentially consequences of adaptation of populations to their agro-ecological conditions, aided by utility value (best practice) to the farmer. This is an important element to guide the development of optimal conservation strategies and subsequently the best place to preserve the genotypes whether in situ or on-farms. On-farm conservation of plant genetic resources is most rational where both the public value of diversity and its private value are high, i.e., areas where there are a lot of genetic diversity and where it makes a substantial contribution to farmers' livelihood [33]. Taken together, the results suggest that agro-morphological characters are highly variable among the landraces and, if looked at holistically, they highlight the difficulty of using them as sole markers for delineating different groups or even in diversity studies. The characters in the above-mentioned clusters are important to farmers specially to spread risk during critical unpredictable climate changes, such as, the global warming phenomenon. This clustering pattern will help in formulating actual breeding strategies.

\section{CONCLUSIONS}

Both the univariate and multivariate analysis of the agro-morphological traits clearly showed the existence of wide variation among the landraces. Moreover, these variations are well spread under the diverse agro-ecological situations. Otherwise, these would have vanished by the time. This is more vivid from the fact that farmers still maintain these landraces and they maintain these for risk management and optimization of production factors well matching with different water, soil regimes, other environmental and economic factors relating to different uses. For each and every character, these variations could be exploited in improvement program. The study also suggests direct selection of the traits, like, leaf length, plant height, culm diameter, culm number, number of grains panicle ${ }^{-1}$ and grain length/breadth ratio for crop improvement for future breeding program. Also, the promising landraces, like, Sarkele-aman, Jhingasal, Annada, Lalhusri, Asanlaya, Sankarkalma, Rupsal, Muktasal and, Chandrakanta can be used as a reservoir of beneficial gene pool in developing high yielding varieties. Multivariate clustering pattern could also suggest the breeders about the suitability of different landraces of rice for breeding program.

\section{ACKNOWLEDGEMENT}

The authors acknowledge the Head of the Department of Botany, K.U. for providing facilities in the Department and Dr. A. Ghosh (Z.A.R.S) for necessary help and assistance.

\section{RECOMMENDATION}

It can be recommended from this study that the traditional rice lines offer a valuable gene pool for utilization in future breeding program. The evaluation of these materials will help the researcher, breeders and farmers to select the desirable traits for utilization in breeding purposes and to identify their stability and response to different environmental conditions. 


\section{COMPETING INTERESTS}

Authors have declared that no competing interests exist.

\section{REFERENCES}

1. Abodolereza A, Racionzer P. Food Outlook: Global Market Analysis. 2009;23-27. Accessed December 2009. Available: www.fao.org/docrep/012/ak341f/ak341f00.

2. Walia US, Walia MK. Scope of direct seeded rice in India. Proc. Biennial Conf. ISWS on News and Emerging Issues in Weed Science. 2-3 November, HAU, Hissar, India. 2007;pp.20.

3. Anonymous. Area and Production of rice in India. 2009a. Available: http/www.indiastat.com.

4. Dey N, Biswas S, Ray Chaudhury T, Dey SR, De M, Ghose TK. RAPD based genetic diversity analysis of aromatic rice (O. sativa L.). Plant Cell Biotechnology and Molecular Biology. 2005;6:133-142.

5. Chattopadhyay T, Biswas T, Chatterjee M, Mandal N, Bhattacharya S. Biochemical and SSR marker based characterization of some Bengal landraces of rice suffixed with 'sail' in their name. Indian J. Genet. 2008;68(1):15-20.

6. Mohammmadi-Najad G, Arzani A, Rezai AM, Singh RK, Gregerio GB. Assessment of rice genotypes for salt tolerance using microsatellite markers associated with the saltol QTL. African Journal of Biotechnology. 2008;7(6):730-736.

7. Chaudhury VS, Singh BB. Heterosis and genetic variability in relation to genetic diversity in Soybean. Indian J. Genet. 1982;42:324-328.

8. Adebisi MA, Ariyo OJ, Kehlnde OB. Variation and Correlation studies in quantitative characteristics in Soybean. Proceedings of the $35^{\text {th }}$ Annual Conference of the Agricultural Society of Nigeria held at the University of Agriculture, Abeokuta, Sept. 2001;16-20:121-125.

9. Richharia RH. An aspect of Genetic Diversity in Rice. Oryza. 1979;16:1-31.

10. Patra BC. Collection and characterization of rice genetic resources from Keonjhar district of Orissa. Oryza. 2000;34:324-326.

11. Cox TS, Murphy JP, Rodgers DM. Changes in the genetic diversity in the red winter wheat regions of the United States. Proc. Natl. Acad. Sci., (USA). 1986;83:5583-6.

12. Barrett BA, Kidwell KK. AFLP based genetic diversity assessment among wheat cultivars from the Pacific Northwest. Crop Sci. 1998;38:1261-71.

13. Thompson JA, Nelson RL, Vodkin LO. Identification of diverse soybean germplasm using RAPD markers. Crop Sci. 1998;38:1348-55.

14. Ariyo ON. Multivariate analysis and choice of parents hybridization in Okra ( $A$. esculentus). Ann. Apl. Biol. 1987;116:335-341.

15. Nair NV, Balakrishan R, Screenivasan TV. Variability for quantitative traits in exotic hybrid germplasm of sugarcane. Genet. Res. Crop Evol. 1998;45:459-464.

16. Omokhafe KO, Alika JE. Multivariate of agronomic data on Hevea brasiliensis. In: Nokoe, S.(Ed). Biometry and qualiy of life. Proceedings of SUSAN-IBS Meting, 23-27 August, 1999, Ibadan, Nigeria, SUSAN-IBS, Nairobi, Kenya. 2000;168-173.

17. Nassir A. Studies on genotypexenvironment interactions, variability and plant character correlation in rice. Ph D Thesis, University of Agriculture, Abeokuta, Nigeria. 2002;123.

18. Mponda OKK, Gobbon D, Arthur E, Morse S. Involving farmers in the design of a low input control programme for sesame flea beatles in Southern Tanzania. Experimental Agriculture. 1997;33(3):313-20. 
19. Verma SP, Rai M. Genetic variability and inter-relation in cassava (Manihot esculenta Crantz) under rainfed conditions of Tripura. J. Root Crops. 1993;19(2):77-80.

20. Steel RGD, Torrie JH, Dickey DA. Principles and Procedures of Statistics: A Biometrical Approach. $3^{\text {rd }}$ ed. New York: McGraw Hill Book Co. Inc.;1997.

21. Chakravorty Ashim, Ghosh PD. An analysis on genetic parameters of different landraces of rice of West Bengal. Journal of Crop and Weed. 2011;7(2):59-63.

22. Cheema AA, Awan MA, Iqbal J. Improvement of Plant Height Architecture in Basmati Rice. Pakistan J. Agric. Res. 1987;8:371-4.

23. Abbasi FM, Sagar MA, Akram M, Ashraf M. Agronomic and quality traits of some elite rice genotypes. Pakistan J. Sci. Indust. Res. 1995;38:348-50.

24. Hirano H, Nakamura A, Kikuchi F, Komatsu S. Protein encoded by genes linked with semidwerfing gene in Rice. Japan Agri. Res. Quart. 1992;25:223-9.

25. Duncun WG. Leaf angle, leaf area and canopy photosynthesis. Crop Sci. 1971;11:482-5.

26. Chang TT, Tagumpay O. Genotypic association between grain yield and six agronomic traits in a cross between rice varieties of contrasting plant types. Euphytica. 1970;19:356-63.

27. Adair CR, et al. Rice breeding and testing methods in the United States.IN: Rice in the United States varieties and production. U.S. Dept. Agric. HandBook-289(revised); 1973:22-25.

28. Akram M, Abbasi FM, Sagar MA, Ashraf M. Increasing rice productivity through better utilization of germplasm. In: Proc. of a Nat. Semi. On Genetic Resources of Cereals and their Utilization. Islamabad, Pakistan. 1994;107-14.

29. Johnson HW, Robinson HF, Comstock RE. Estimates of genetic and environmental variability in Soybeans. Agron. J. 1955;47:314-318.

30. Panse G. Genetic of quantitative characters in relation to plant breeding. Ind. J. Genet. 1957; 17:318-329.

31. Burton GW. Quantitative inheritance of grasses, Proc. VI. Int. Grassld. Congr. 1952;1:277-283.

32. Gandhi SM, Sangi AK, Nathawat KS, Bhatnagar MP. Genotypic variability and correlation relating to grain yield and few other quantitative characters in Indian Wheat. Indian J. Genet. 1964;24:1-8.

33. Smale M, Bellon MR, Jarvis D, Sthapit B. Economic concepts for Designing Policies to Conserve Crop Genetic Resources On Farms. Genet. Res. Crop. Evol. 2004;51:121135.

(c) 2013 Chakravorty et al.; This is an Open Access article distributed under the terms of the Creative Commons Attribution License (http://creativecommons.org/licenses/by/3.0), which permits unrestricted use, distribution, and reproduction in any medium, provided the original work is properly cited.

Peer-review history:

The peer review history for this paper can be accessed here: http://www.sciencedomain.org/review-history.php?iid=156\&id=2\&aid=808 